\section{Outgoing Editor-in-Chief}

Dear Readers

I have had a terrific four years as Editor-in-Chief of Reproduction. The opportunity to work with the Editorial Board, referees and authors has been a real benefit of the job. I had not anticipated the level of support and commitment from everyone who has been involved with the journal and I would like to take this opportunity to thank everyone for their contributions.

As Editor-in-Chief, I have been exposed to a wider gamut of research in reproductive biology than I had previously known existed. In all cases, we have tried to focus on publishing the most rigorous and the most exciting manuscripts. I hope this has resulted in a journal that meets the needs of the research community and one that points to the vigour of the research activity in the field of reproductive biology.

I also need to thank two groups of individuals whose presence and association with the journal is not always as visible as it should be. Firstly, all the staff at BioScientifica: Lindsay and Paul who have provided all of the support and management of the peer review process, Andrew and Sarah who have continually strived for excellence in the quality of the production and, of course, Steve Byford who has led the team from the front and provided a demeanour of calm and steely determination in the face of a number of important decisions.

Secondly, the Society for Reproduction and Fertility, the Council of which has ultimate responsibility for the journal. Under the leadership of Alan McNeilly (yes Alan, I still have a twinge in my shoulder) and more recently Helen Picton, the journal has been able to move to a new publisher and into the electronic publishing age quickly and efficiently.

Scientific publishing faces many big questions in the near future. The future of the subscription-based model, the future of print journals and the ultimate impact of the drive for open access: these questions will no doubt reshape how we publish our research in the future. Undoubtedly, the most important contribution of my tenure has been to identify the person to take the journal through these challenges. Tom Fleming has energy, insight and an eye for quality (Southampton Saints notwithstanding) that will ensure that the journal moves from strength to strength in the future.

Thanks again to everyone who has contributed to the journal over the last four years and, finally, good luck Tom!

\section{Incoming Editor-in-Chief}

Dear Readers

I am very excited and honoured to be taking over the position of Editor-in-Chief for Reproduction, a journal with a leading international reputation for quality and innovation in reproductive biology. My predecessor, John Carroll, will be a tough act to follow but I am up for the challenge. During his four years as Editor, John has enhanced the scientific excellence of the journal with stronger emphasis on the publication of cellular and molecular mechanisms underpinning reproductive processes. His leadership has also provided us with all the benefits of a modern and efficient online interface for manuscript submission, peer-review processing and journal access. Reproduction has been further strengthened by John's introduction of Reviews and Focus issues to complement the normal research paper format. All of these improvements have helped to promote the perceived quality and esteem factors of the journal - thanks, John, for your wisdom and sustained effort: enjoy the beer in the sun, it is well earned. Thanks also to all the Editorial Board members, reviewers and indeed the authors, together with our publishers, BioScientifica, for their significant contribution in the upward progression of our journal.

Reproduction will continue to be a leading voice for scientific innovation and excellence in reproductive biology. Our field is one that is changing as new biotechnologies are developed and concepts are proposed. Reproductive biology is a dynamic and all-pervasive subject. It spans from molecular, genetic and epigenetic detail, through cellular and developmental biology, to physiological and whole-organism biology. Moreover, adult phenotype and health have now been shown to be dependent upon the success of homeostatic processes taking place during the reproductive cycle. Whilst our subject is broadening, reflecting the central importance of reproductive biology in the life sciences, this journal will continue its mission to publish quality papers with clear and novel insight into reproductive mechanisms at all levels of biological organization. Authors and readers, make Reproduction the home for your very best work. 